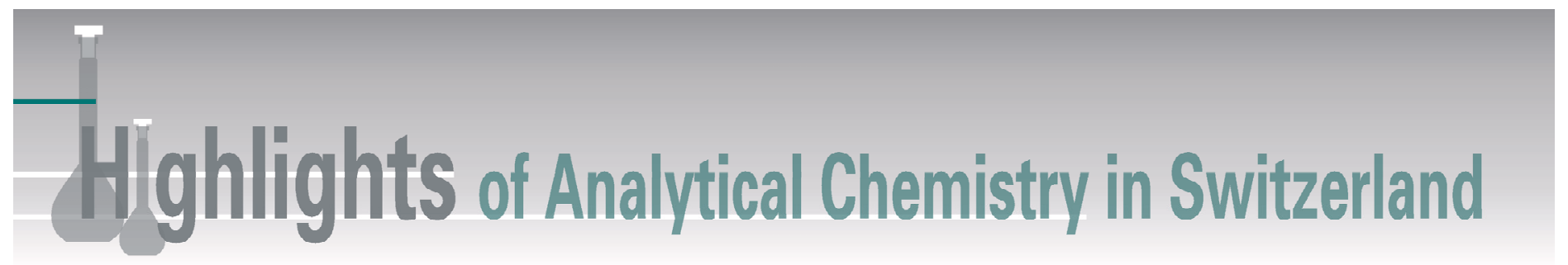

\section{Investigations of Ancient Lead White Pigments Using Lead Isotope Abundance Ratios}

\author{
Giuseppino Fortunato ${ }^{a \star}$, Axel Ritter $^{a}$, and Daniel Fabian ${ }^{b}$ \\ aEMPA St. Gallen; ' ${ }^{b}$ Fabian \& Samuels, Stäfa
}

${ }^{*}$ Correspondence: Dr. G. Fortunato, Functional Fibers and Textiles, EMPA St. Gallen, Lerchenfeldstr. 5, $\mathrm{CH}-9014$ St. Gallen

Tel.: +41 7127476 77, Fax: +41 7127478 62, E-Mail: giuseppino.fortunato@empa.ch

\section{Keywords: Arts · Lead isotope ratio - Lead white · Provenance}

Lead white $\left(2 \mathrm{PbCO}_{3} \cdot \mathrm{Pb}(\mathrm{OH})_{2}\right)$, a common component in 17 th century artists' painting materials, was singled out to study the potential and limits of lead isotope abundance ratios in the field of origin assignment. Paintings by P.P. Rubens, A. van Dyck and other old masters were chosen for this study.

Natural lead consists of four isotopes, ${ }^{204} \mathrm{~Pb},{ }^{206} \mathrm{~Pb},{ }^{207} \mathrm{~Pb}$, and ${ }^{208} \mathrm{~Pb}$. The last three isotopes derive partly from the radioactive decay of the nuclides of uranium $\left({ }^{238} \mathrm{U}\right.$ and $\left.{ }^{235} \mathrm{U}\right)$ and thorium $\left({ }^{232} \mathrm{Th}\right)$. The isotopic compositions depend primarily on the age as well as on the $\mathrm{U} / \mathrm{Pb}$ and $\mathrm{Th} / \mathrm{Pb}$ amount content ratios of the rocks forming the ore deposits from which the lead was extracted. Historically, lead was among the first metals extracted from ores by man, and because it is abundant in nature and relatively inexpensive, lead is found on a great many archaeological sites. The principle of object provenancing is to make comparative isotopic analyses of the lead present in artifacts and in a sufficient number of ore deposits.

Minute samples (50-200 $\mu \mathrm{g}$ ) taken from paintings from art collections worldwide were investigated using multi-collector inductively coupled mass spectrometry (MC-ICP-MS), scanning electron microscopy (SEM) and energy-dispersive X-ray spectroscopy (EDX).

The scatter plots of the measured isotope abundance ratios of the painting pigments from P.P. Rubens, A. van Dyck and other Flemish painters show a very narrow distribution forming a cluster with relative widths of $0.55 \%$ and $0.2 \%$. The comparison of these data with cis-alpine (Italian) sample pigments from paintings of the same time period reveals a clear distinction between the isotopic arrays. With respect to European ore lead isotope data we assume that the pigment isotope ratio distribution is a direct representation of the very distinct origin of raw materials. Presumably, no mixing of different lead ores from Europe took place. The comparison of the measured white lead isotope ratio values (Flemish paintings) and the data from ore samples lead to the unexpected conclusion that British or German products and not local ores were used for the pigment production.

The results to date show great promise as a further tool in the identification and authentication of works of art. It is now important to build up a white lead data base and to examine the lead ore isotope ratio values in a more detailed way.

Received: March 1, 2005

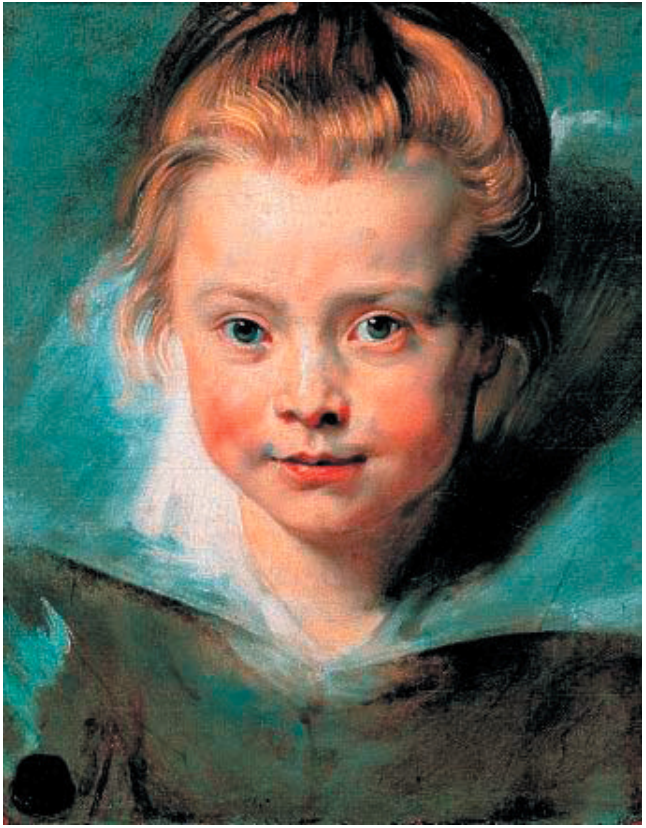

One of the investigated paintings: Peter Paul Rubens, Clara Serena Rubens, 1616, Oil on Canvas, Collections of the Prince of Liechtenstein, VaduzVienna

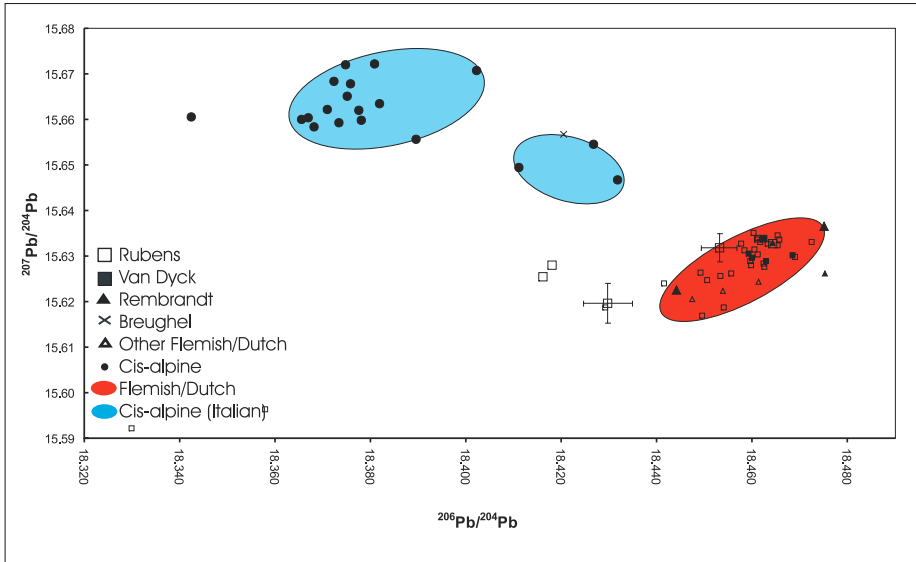

Lead isotope abundance ratio values for cis- and trans-alpine pigment samples. Bars denote typical combined measurement uncertainties (coverage factor $\mathrm{k}=2$ )

\section{Acknowledgements}

We thank the following persons and institutions for their help and support: HSH Prince Hans-Adam II of Liechtenstein, Vaduz and the Swiss National Science Foundation.

\section{Reference}

G. Fortunato, A. Ritter, D. Fabian, Analyst 2005, in press. 